\title{
FORMULATION AND OPTIMIZATION OF MUCOADHESIVE MICROSPHERES OF VALSARTAN BY USING BOX-BEHNKEN DESIGN
}

\author{
CHIMAN LAL ${ }^{1}$, RAJEEV GARG², GHANSHYAM DAS GUPTA ${ }^{3}$
}

1I. K. G. Punjab Technical University, Kapurthala 144603, Punjab, India, ${ }^{2}$ Amar Shaheed Baba Ajit Singh Jujhar Singh Memorial College of Pharmacy, Bela, Ropar, Punjab, India 140111, 3I. S. F. College of Pharmacy, Moga, Punjab, India 142001

Email: chimanberi22@gmail.com

Received: 23 Apr 2019, Revised and Accepted: 01 Jun 2019

\section{ABSTRACT}

Objective: The purpose of this study was to formulate and optimize mucoadhesive microspheres of antihypertensive drug (valsartan) within ethyl cellulose as a carrier polymer and carbopol 934P as a mucoadhesive polymer for controlling the release of valsartan.

Methods: The emulsion solvent evaporation technique was used for preparation of microspheres of valsartan and the Box-Behnken design was employed with thee independent variables that is amount of ethyl cellulose $\left(\mathrm{X}_{1}\right)$ and amount of carbopol 934P $\left(\mathrm{X}_{2}\right)$ and stirring speed $\left(\mathrm{X}_{3}\right)$ and evaluate four dependent variables such as percentage mucoadhesion, $\mathrm{Q}_{1} \mathrm{~h}, \mathrm{t}_{90} \%$ and drug entrapment efficiency.

Results: The optimum conditions were found to be $X_{1}=200 \mathrm{mg}, X_{2}=107 \mathrm{mg}$ and $X_{3}=1200 \mathrm{rpm}$. The optimized batch exhibited a high drug entrapment efficiency of $85.63 \pm 1.384 \%$, percentage mucoadhesion was $66.76 \pm 0.986 \%$ and drug release was also sustained for more than $12 \mathrm{~h}$.

Conclusion: The analysis of variance showed a significant effect of independent variables. The scaning electron microscopy (SEM) analysis showed that the microspheres were spherical and free-flowing. The microspheres of valsartan were stable after thee month stability study at accelerated condition.

Keywords: Mucoadhesive microspheres, Valsartan, Carbopol 934P, Ethylcellulose, Box-Behnken design

(C) 2019 The Authors. Published by Innovare Academic Sciences Pvt Ltd. This is an open access article under the CC BY license (http://creativecommons.org/licenses/by/4.0/) DOI: http://dx.doi.org/10.22159/ijap.2019v11i4.33710

\section{INTRODUCTION}

Hypertension is one of the primary risk factors for heart disease and stroke, the leading causes of death due to its high prevalence all around the globe [1-4]. Approximately 7.5 million deaths worldwide occur due to hypertension and predicted to be increased to 1.56 billion adults with high blood pressure in 2025 [5, 6].

A number of different types of anti-hypertensive agents used to control elevated blood pressure [7]. Valsartan, a non-peptide, specific competitive angiotensin II type 1 receptor antagonist is a drug of choice in cardiovascular disorders, particularly in hypertension $[8,9]$.

The oral route is most convenient for the delivery of different dosage form as compared with other routes [10]. The absorption of valsartan is high (tmax $\approx 2$ ) through oral administration, but it has poor bioavailability (23\%) due to slow absorption from the gastrointestinal tract. Therefore, improving its therapeutic efficacy through oral route alternative drug delivery systems and dosage forms is needed [11-13].

Various investigations have confirmed that a gastro-retentive mucoadhesive delivery system could remain in the gastric mucosa for a long period of time and it improves the bioavailability and reduce drug loss $[14,15]$. Moreover, it could play an effective role in drug localization in the stomach $[16,17]$. The high surface-tovolume ratio of this dosage form could improve drug absorption and drug bioavailability $[18,19]$.

In this work, mucoadhesive microspheres of valsartan were prepared with carbopol $934 \mathrm{P}$ as mucoadhesive and ethyl cellulose as carrier polymer by using the emulsion solvent evaporation technique. A Box-Behnken design was employed to study the effect of independent variables (amount of ethyl cellulose, amount of carbopol 934P and stirring speed) of mucoadhesive microspheres of valsartan on the physicochemical characteristics (drug entrapment efficiency, $\mathrm{Q}_{1} \mathrm{~h}, \mathrm{t}_{90 \%}$ and mucoadhesion).

\section{MATERIALS AND METHODS}

\section{Materials}

Valsartan was obtained from Macleods Pharmaceutical Ltd. Sarigam (Gujarat, India). Carbopol 934P was purchased from sigma Aldrich
Pvt. Ltd. Ethylcellulose, light liquid paraffin, Span 80, Ethanol 95\%, petroleum ether, and methanol were purchased from Loba Chemie Pvt. Ltd. Mumbai. Hydrochloric acid $(\mathrm{HCl})$ was purchased from Thermo Fisher Scientific India Pvt. Ltd. Mumbai. All other chemicals were of analytical grade.

\section{Preparation of microspheres}

Mucoadhesive microspheres of valsartan were prepared with an emulsion solvent evaporation technique. Ethyl cellulose was dissolved in $95 \%$ ethanol; carbopol 934P and valsartan powder were added in ethyl cellulose solution under magnetic stirring for $2 \mathrm{~h}$. Then this suspension was dispersed dropwise in light liquid paraffin containing span 80 as surfactant with continuous stirring on Remi mechanical stirrer at 1000 $\mathrm{rpm}$. After $5 \mathrm{~h}$ of stirring, ethanol was evaporated gradually and microspheres were produced. Prepared microspheres were washed with petroleum ether, filtered, dried at room temperature for $24 \mathrm{~h}$ and then stored in the desiccators until used.

\section{Box-behnken optimization design}

The box-behnken design was employed for optimizing the microspheres of valsartan and investigating the correlation between the experimental factors and responses.

The independent factors chosen in the Box-Behnken design were: the amount of ethyl cellulose $\left(\mathrm{X}_{1}\right)$, amount of carbopol 934P $\left(\mathrm{X}_{2}\right)$ and stirring speed $\left(\mathrm{X}_{3}\right)$. The levels of the factors are selected according to the literature $[20,21]$. Twelve batches of microspheres and thee center point batches were prepared according to this design.

In order to elucidate the effect of preparation conditions on dependent variables such as encapsulation efficiency, $Q_{1} h, t_{90 \%}$ and mucoadhesion, the Box-Behnken design was used with the three factors selected and their respective thee levels (low, medium and high). To evaluate the response variables, a second-order polynomial model was utilized:

$Y=\beta_{0}+\beta_{1} x_{1}+\beta_{2} x_{2}+\beta_{3} x_{3}+\beta_{12} x_{1} x_{2}+\beta_{13} x_{1} x_{3}+\beta_{23} x_{2} x_{3}+\beta_{11} x_{1}{ }^{2}+\beta_{22} x_{2}{ }^{2}+\beta_{3}$
${ }_{3} x_{3}{ }^{2} \ldots$ (Eq.1)

$Y$ is the predicted response; $\beta_{0}$ is model constant; $x_{1}, x_{2}$, and $x_{3}$ are independent variables; $\beta_{1}, \beta_{2}$, and $\beta_{3}$ are linear coefficients; $\beta_{12}, \beta_{13}$ and $\beta_{23}$ are cross-product coefficients; and $\beta_{11}, \beta_{22}$, and $\beta_{33}$ are the 
quadratic coefficients. The quality of fit of the polynomial model equation was expressed with the coefficient of determination $R^{2}$
[22]. The selection of independent and dependent variables and their levels are given in table 1.

Table 1: Independent and dependent variables

\begin{tabular}{lll}
\hline Independent variable & Variable level & Medium (0) \\
\cline { 2 - 3 } & Low (-1) & $150 \mathrm{mg}$ \\
\hline Amount of ethyl cellulose $\left(\mathrm{X}_{1}\right)$ & $100 \mathrm{mg}$ & $100 \mathrm{mg}$ \\
Amount of carbopol 934P $\left(\mathrm{X}_{2}\right)$ & $50 \mathrm{mg}$ & 1000 \\
Stirring speed $\left(\mathrm{X}_{3}\right)$ & 800 & $150 \mathrm{mg}$ \\
Dependent Variables & & 1200
\end{tabular}

$\mathrm{Y}_{1}=$ percent entrapment efficiency, $\mathrm{Y}_{2}=\mathrm{Q}_{1 \mathrm{~h}}$ (percent cumulative drug release at $1 \mathrm{~h}$ ), $\mathrm{Y}_{3}=\mathrm{t}_{90 \%}, \mathrm{Y}_{4}=$ percent mucoadhesion

\section{Determination of percentage yield}

The production yields of mucoadhesive microspheres of all formulation batches were evaluated using the weight of the final dried product (W1) with respect to the initial total weight of the raw materials used for the preparation of microspheres (W2) and percent production yields according to the equation 2 cited below [23-25].

$$
\% \text { yield }=\frac{\text { Total amount of dried microspheres (W1) }}{\text { Total weight of raw material (W2) }} \times 100 \text {. (Eq. 2) }
$$

\section{Determination of drug entrapment efficiency}

A precisely measured amount of mucoadhesive microspheres (50 mg) of valsartan was dissolved in methanol with stirring until complete dissolution. The solution was then filtered, an aliquot of the filtrate was appropriately diluted, and the content of valsartan was determined spectrophotometrically at $248 \mathrm{~nm}$. The determinations were made in triplicate. The percent drug entrapment efficiency was determined according to the following equation [26-28].

$\%$ Entrapment efficiency $=\frac{\text { Practical drug loading }}{\text { Theoretical drug loading }} \times 100 \ldots$ (Eq. 3$)$

\section{Determination of particle size of microspheres}

The microsphere was examined with an optical microscope and the size of the microspheres was calculated with a pre-calibrated ocular micrometer and stage micrometer. About 200-300 particles of each formulation were observed and counted [29-31].

\section{In vitro release study}

An appropriate amount of Microspheres (50 mg) was taken in a muslin cloth. Dissolution was performed using USP type II apparatus at $37 \pm 0.5^{\circ} \mathrm{C}$, rotational speed of $50 \mathrm{rpm}$ in $900 \mathrm{ml}$ of $0.1 \mathrm{~N} \mathrm{HCL} \mathrm{(pH} \mathrm{1.2)} \mathrm{for}$ $12 \mathrm{~h}$. Samples $(5 \mathrm{ml})$ were withdrawn at fixed time intervals and equally $(5 \mathrm{ml})$ replaced with fresh dissolution medium $[32,33]$, filtered, diluted suitably and analyzed spectrophotometrically at $249 \mathrm{~nm}$. Concentrations were calculated using calibration curves developed in respective media. Taking into account, the loss of the drug in aliquot replaced, the correction factor was used as shown in equation 4 [34-36].

$$
\mathrm{C}_{\mathrm{i}}=\mathrm{Ai}+\frac{\mathrm{Vs}}{\mathrm{Vt}} \sum_{\mathrm{i}=1}^{\mathrm{n}-1} \mathrm{Ai}\left(\frac{\mathrm{Vt}}{\mathrm{Vt}-\mathrm{Vs}}\right)
$$

Where, $\mathrm{C}_{\mathrm{i}}=$ Corrected absorbance, $\mathrm{V}_{\mathrm{s}}=$ Sample of dissolution media withdrawn, $\mathrm{V}_{\mathrm{t}}=$ Total volume of dissolution media.

Dissolution release profiles were plotted with percentage drug released at different time intervals. $\mathrm{Q}_{1} \mathrm{~h}$ percent cumulative drug release (\% CDR) and the average value of $t_{90 \%}$ for all batches was calculated from the dissolution data.

\section{In vitro wash-off test}

Mucoadhesive property of Microspheres was evaluated by In vitro wash-off test. The rats were sacrificed by cervical dislocation. The abdomen was opened and the stomach excised [37]. A $1-\mathrm{cm}$ by $1-\mathrm{cm}$ piece of rat stomach mucosa was cut and tied on a glass slide (3-inch by 1 -inch) with thead. Approximately 100 microspheres were spread onto the wet rinsed tissue specimen and hanging prepared slide onto the grooves of a USP tablet disintegrating test apparatus. After that, the apparatus was switched on and the tissue specimen was given up and down movements for $10 \mathrm{~h}$ in a beaker having simulated gastric fluid $(\mathrm{pH}$ 1.2). The microspheres left behind on the surface of the gastric mucosa were counted after $10 \mathrm{~h}$ and the \% mucoadhesion was calculated by the formula shown in Equation $5[38,39]$.

$$
\text { Percent mucoadhesion }=\frac{\text { Weight of adhered microspheres }}{\text { Weight of applied microspheres }} \times 100 \ldots \text { (Eq. 5) }
$$

\section{Release kinetics and mechanism}

To determine the release mechanism and kinetics, optimized formulation was attempted to fit into different mathematical models like zero order, first order, Higuchi's Hixon-Crownwell and

\begin{tabular}{|c|c|c|c|c|c|c|c|}
\hline \multirow[b]{2}{*}{$\begin{array}{l}\text { Batch } \\
\text { No. }\end{array}$} & \multicolumn{3}{|c|}{ Independent factors } & \multicolumn{4}{|l|}{ Responses } \\
\hline & $\begin{array}{l}\text { Amount of ethyl } \\
\text { cellulose (mg) }\end{array}$ & $\begin{array}{l}\text { Amount of carbopol } \\
\text { 934P(mg) }\end{array}$ & $\begin{array}{l}\text { Stirring speed } \\
\text { (rpm) }\end{array}$ & $\begin{array}{l}\text { Entrapment } \\
\text { efficiency* (\%) }\end{array}$ & $\begin{array}{l}\mathbf{Q}_{1} \mathbf{h} \\
\text { (\%CDR)* }\end{array}$ & $\begin{array}{l}t_{90 \%} \\
\text { (min.) }\end{array}$ & $\begin{array}{l}\text { Mucoadhesion } \\
(\%)\end{array}$ \\
\hline $\begin{array}{l}V_{1} \\
\end{array}$ & $-1(100)$ & $1(150)$ & $0(1000)$ & $56.18 \pm 1.12$ & $34.76 \pm 0.83$ & 498 & 74 \\
\hline $\mathrm{V}_{2}$ & $-1(100)$ & $0(100)$ & $1(1200)$ & $57.54 \pm 0.25$ & $25.34 \pm 1.02$ & 538 & 67 \\
\hline $\mathrm{V}_{3}$ & $1(200)$ & $-1(50)$ & $0(1000)$ & $74.66 \pm 0.68$ & $22.24 \pm 0.95$ & 725 & 51 \\
\hline $\mathrm{V}_{4}$ & $1(200)$ & $0(100)$ & $1(1200)$ & $87.32 \pm 2.32$ & $18.72 \pm 0.79$ & 745 & 64 \\
\hline$V_{5}$ & $1(200)$ & $0(100)$ & $-1(800)$ & $78.86 \pm 1.62$ & $26.86 \pm 0.13$ & 636 & 65 \\
\hline $\mathrm{V}_{6}$ & $1(200)$ & $1(150)$ & $0(1000)$ & $85.16 \pm 0.58$ & $28.48 \pm 1.58$ & 558 & 68 \\
\hline$V_{7}$ & $-1(100)$ & $-1(50)$ & $0(1000)$ & $51.68 \pm 0.74$ & $33.56 \pm 0.90$ & 612 & 54 \\
\hline $\mathrm{V}_{8}$ & $0(150)$ & $-1(50)$ & $1(1200)$ & $62.54 \pm 3.62$ & $23.26 \pm 1.03$ & 716 & 52 \\
\hline $\mathrm{V}_{9}$ & $0(150)$ & $1(150)$ & $-1(800)$ & $60.65 \pm 1.23$ & $32.85 \pm 0.30$ & 538 & 72 \\
\hline $\mathrm{V}_{10}$ & $0(150)$ & $1(150)$ & $1(1200)$ & $64.94 \pm 2.22$ & $24.98 \pm 0.72$ & 568 & 69 \\
\hline$V_{11}$ & $0(150)$ & $0(100)$ & $0(1000)$ & $56.38 \pm 0.26$ & $25.26 \pm 1.14$ & 547 & 62 \\
\hline $\mathrm{V}_{12}$ & $-1(100)$ & $0(100)$ & $-1(800)$ & $50.45 \pm 2.32$ & $35.66 \pm 1.16$ & 524 & 70 \\
\hline $\mathrm{V}_{13}$ & $0(150)$ & $0(100)$ & $0(1000)$ & $58.76 \pm 2.47$ & $23.64 \pm 1.07$ & 556 & 60 \\
\hline $\mathrm{V}_{14}$ & $0(150)$ & $0(100)$ & $0(1000)$ & $58.12 \pm 0.16$ & $23.88 \pm 0.90$ & 576 & 62 \\
\hline$V_{15}$ & $0(150)$ & $-1(50)$ & $-1(800)$ & $53.76 \pm 0.72$ & $31.08 \pm 1.75$ & 628 & 52 \\
\hline
\end{tabular}
Korsmeyer-Peppas models [40, 41].

Table 2: Experiment plan and observed responses of the model

${ }^{*}$ mean \pm SD, $\mathrm{n}=3$ 


\section{Determination of surface morphology}

Scanning electron microscope (SEM) (JEOL JSM-6100 scanning microscope, Japan) was used to determine surface characteristics of microspheres. Sample of microspheres was mounted on a stub and coated with a layer of gold using a sputter coater (JFC-1100). The samples were scanned at $5 \mathrm{kV}$ and photomicrograph at different magnification ratio [42].

\section{RESULTS AND DISCUSSION}

\section{Optimization}

In the Box-Behnken design, a total 15 formulations were proposed by Design expert software for thee factors such as the amount of ethyl cellulose $\left(\mathrm{X}_{1}\right)$, amount of carbopol 934P $\left(\mathrm{X}_{2}\right)$ and stirring speed $\left(X_{3}\right)$, which were varied at thee different levels $(-1,0$ and 1$)$. The effects of independent variables (factors) on the drug entrapment efficiency (\%), $\mathrm{Q}_{1} \mathrm{~h}(\%), \mathrm{t}_{90 \%}$ and mucoadhesion (\%) were examined as optimization response parameters in this study. Summarize of the experimental plan and observed responses were presented in table 2 and the percent yield, particle size and shape of microspheres were shown in table 3 .

The polynomial equation for entrapment efficiency as follows, according to the model:

$\mathrm{Y}_{1}=+57.75+13.77 \mathrm{X}_{1}+3.04 \mathrm{X}_{2}+3.58 \mathrm{X}_{3}+1.50 \mathrm{X}_{1} \mathrm{X}_{2}+0.3425 \mathrm{X}_{1} \mathrm{X}_{3}-1.12 \mathrm{X}_{2}$ $\mathrm{X}_{3}+8.62 \mathrm{X}_{1}^{2}+0.5483 \mathrm{X}_{2}^{2}+2.17 \mathrm{X}_{3}^{2}$

The F-value of 86.85 implies the model is significant $(\mathrm{p}<0.0001)$ (table 4). So the $X_{1}, X_{2}, X_{3}, X_{1}{ }^{2}$ and $X_{3}{ }^{2}$ are significant model terms. The 'Pred R-Squared' of 0.9191 is in rational agreement with the 'Adj RSquared' of 0.9822.

Table 3: Results of percentage yield, particle size and shape of microspheres

\begin{tabular}{llll}
\hline Batch No. & Percent yield & Particle size* $\mathbf{( u m})$ & Shape of microspheres \\
\hline $\mathrm{V}_{1}$ & 75.24 & $104.28 \pm 2.64$ & Spherical \\
$\mathrm{V}_{2}$ & 82.86 & $92.64 \pm 2.84$ & Spherical \\
$\mathrm{V}_{3}$ & 78.52 & $98.84 \pm 3.67$ & Spherical \\
$\mathrm{V}_{4}$ & 87.64 & $95.21 \pm 2.34$ & Spherical \\
$\mathrm{V}_{5}$ & 70.16 & $124.32 \pm 3.98$ & Spherical \\
$\mathrm{V}_{6}$ & 82.34 & $118.16 \pm 3.24$ & Spherical \\
$\mathrm{V}_{7}$ & 73.28 & $96.74 \pm 1.82$ & Spherical \\
$\mathrm{V}_{8}$ & 83.25 & $95.98 \pm 2.73$ & Spherical \\
$\mathrm{V}_{9}$ & 71.86 & $120.22 \pm 4.16$ & Spherical \\
$\mathrm{V}_{10}$ & 87.36 & $93.96 \pm 3.14$ & Spherical \\
$\mathrm{V}_{11}$ & 72.56 & $108.62 \pm 3.21$ & Spherical \\
$\mathrm{V}_{12}$ & 68.14 & $112.26 \pm 2.63$ & Spherical \\
$\mathrm{V}_{13}$ & 74.64 & $106.92 \pm 2.85$ & Spherical \\
$\mathrm{V}_{14}$ & 76.86 & $108.56 \pm 1.64$ & Spherical \\
$\mathrm{V}_{15}$ & 74.52 & $114.76 \pm 3.93$ & Spherical \\
\hline
\end{tabular}

*mean \pm SD, $\mathrm{n}=3$

Table 4: Analysis of variance calculated for responses

\begin{tabular}{|c|c|c|c|c|}
\hline Batch No. & Entrapment efficiency & $\mathbf{Q}_{1} \mathbf{h}$ & $\mathbf{t}_{90 \%}$ & Mucoadhesion \\
\hline Regression sum of square & 1990.15 & 360.32 & 80885.92 & 807.48 \\
\hline $\mathrm{df}$ & 9 & 9 & 9 & 9 \\
\hline Mean square & 221.13 & 40.04 & 8987.32 & 89.72 \\
\hline F-value & 86.85 & 39.78 & 13.46 & 153.81 \\
\hline p-value & $<0.0001$ & $<0.0004$ & $<0.0053$ & $<0.0001$ \\
\hline Lack of fit sum of square & 9.70 & 3.50 & 2898.75 & 0.2500 \\
\hline df & 3 & 3 & 3 & 3 \\
\hline Mean square & 3.23 & 1.17 & 966.25 & 0.0833 \\
\hline F-value & 2.13 & 1.53 & 4.39 & 0.0625 \\
\hline Correlation coefficient $\left(\mathrm{R}^{2}\right)$ & 0.9936 & 0.9862 & 0.9604 & 0.9964 \\
\hline
\end{tabular}

The polynomial equation for $\mathrm{Q}_{1} \mathrm{~h}$ as follows, according to the model:

$\mathrm{Y}_{1}=+24.26-4.13 \mathrm{X}_{1}+1.37 \mathrm{X}_{2}-4.27 \mathrm{X}_{3}+1.37 \mathrm{X}_{1} \mathrm{X}_{2}+0.5450 \mathrm{X}_{1} \mathrm{X}_{3}-0.0125 \mathrm{X}_{2}$ $\mathrm{X}_{3}+2.05 \mathrm{X}_{1}^{2}+3.45 \mathrm{X}_{2}^{2}+0.3337 \mathrm{X}_{3}^{2}$

The F-value of 39.78 implies the model is significant $(\mathrm{p}<0.0004)$ (table 4). So the $X_{1}, X_{2}, X_{3}, X_{12}, X_{1}^{2}$ and $X_{2}^{2}$ are significant model terms. The 'Pred R-Squared' of 0.8372 is in rational agreement with the 'Adj R-Squared' of 0.9614 .

The polynomial equation for $t_{90 \%}$ as follows, according to the model:

$\mathrm{Y}_{1}=+559.67+61.50 \mathrm{X}_{1}-64.88 \mathrm{X}_{2}+30.13 \mathrm{X}_{3}-13.25 \quad \mathrm{X}_{1} \mathrm{X}_{2}+23.75 \mathrm{X}_{1} \mathrm{X}_{3}-$ $14.50 \mathrm{X}_{2} \mathrm{X}_{3}+18.42 \mathrm{X}_{1}^{2}+20.17 \mathrm{X}_{2}^{2}+32.67 \mathrm{X}_{3}^{2}$

The $F$-value of 13.46 implies the model is significant $(p<0.0053)$ (table 4). So the $X_{1}, X_{2}$ and $X_{3}$ are significant model terms. The 'Pred R-Squared' of 0.4376 is in rational agreement with the 'Adj RSquared' of 0.8890 .

The polynomial equation for mucoadhesion as follows, according to the model:
$Y_{1}=+61.33-2.13 X_{1}+9.25 X_{2}-0.8750 X_{3}-0.7500 \quad X_{1} \quad X_{2}+0.5000 \quad X_{1} \quad X_{3}-$ $0.7500 \mathrm{X}_{2} \mathrm{X}_{3}+2.83 \mathrm{X}_{1}^{2}-2.42 \mathrm{X}_{2}^{2}+2.33 \mathrm{X}_{3}^{2}$

The F-value of 153.81 implies the model is significant $(\mathrm{p}<0.0053)$ (table 4). So the $\mathrm{X}_{1}, \mathrm{X}_{2}, \mathrm{X}_{3}, \mathrm{X}_{1}{ }^{2}, \mathrm{X}_{2}{ }^{2}$ and $\mathrm{X}_{3}{ }^{2}$ are significant model terms. The 'Pred R-Squared' of 0.9877 is in rational agreement with the 'Adj R-Squared' of 0.9890 .

Coefficients with more than one-factor term represent interaction terms and those with second order terms represent quadratic relationships. The coefficient's sign shows how independent factors influence the responses. The positive sign of the coefficient indicates the response increases (synergistic effect), and a negative sign indicates the response decreases (antagonist effect).

For all these formulations proposed by the Box-Behnken design, the results of examining responses (entrapment efficiency, $Q_{1} h, t_{90 \%}$ and mucoadhesion) were found within the limits. The actual and predicted responses for all response variables investigated in this study with the parentage of errors in prognosis are given in table 5. 
Table 5: Actual and predicted responses of all response variables

\begin{tabular}{|c|c|c|c|c|c|c|c|c|}
\hline \multirow[t]{2}{*}{ Batch No. } & \multicolumn{2}{|c|}{ Entrapment efficiency } & \multicolumn{2}{|c|}{$Q_{1} h(\% C D R)$} & \multicolumn{2}{|l|}{$\mathbf{T}_{\mathbf{9 0} \%}$} & \multicolumn{2}{|c|}{ Percent mucoadhesion } \\
\hline & Actual & Pred. & Actual & Pred. & Actual & Pred. & Actual & Pred. \\
\hline$\overline{V_{1}}$ & 56.18 & 54.69 & 34.76 & 33.99 & 498.00 & 485.13 & 74.00 & 73.88 \\
\hline $\mathrm{V}_{2}$ & 57.54 & 58.01 & 25.34 & 25.96 & 538.00 & 555.63 & 67.00 & 67.25 \\
\hline $\mathrm{V}_{3}$ & 74.66 & 76.15 & 22.24 & 23.01 & 725.00 & 737.88 & 51.00 & 51.13 \\
\hline $\mathrm{V}_{4}$ & 87.32 & 86.23 & 18.72 & 18.79 & 745.00 & 726.13 & 64.00 & 64.00 \\
\hline $\mathrm{V}_{5}$ & 78.86 & 78.39 & 26.86 & 26.24 & 636.00 & 618.38 & 65.00 & 64.75 \\
\hline $\mathrm{V}_{6}$ & 85.16 & 85.22 & 28.48 & 28.26 & 558.00 & 581.63 & 68.00 & 68.13 \\
\hline $\mathrm{V}_{7}$ & 51.68 & 51.61 & 33.56 & 33.78 & 612.00 & 588.38 & 54.00 & 53.88 \\
\hline $\mathrm{V}_{8}$ & 62.54 & 62.14 & 23.26 & 22.42 & 716.00 & 722.00 & 52.00 & 51.88 \\
\hline$V_{9}$ & 60.65 & 61.05 & 32.85 & 33.69 & 538.00 & 532.00 & 72.00 & 72.13 \\
\hline $\mathrm{V}_{10}$ & 64.94 & 65.96 & 24.98 & 25.13 & 568.00 & 563.25 & 69.00 & 68.88 \\
\hline $\mathrm{V}_{11}$ & 56.38 & 57.75 & 25.26 & 24.26 & 547.00 & 559.67 & 62.00 & 61.33 \\
\hline $\mathrm{V}_{12}$ & 50.45 & 51.54 & 35.66 & 35.59 & 524.00 & 542.88 & 70.00 & 70.00 \\
\hline $\mathrm{V}_{13}$ & 58.76 & 57.75 & 23.64 & 24.26 & 556.00 & 559.67 & 60.00 & 61.33 \\
\hline $\mathrm{V}_{14}$ & 58.12 & 57.75 & 23.88 & 24.26 & 576.00 & 559.67 & 62.00 & 61.33 \\
\hline $\mathrm{V}_{15}$ & 53.76 & 52.74 & 31.08 & 30.93 & 628.00 & 632.75 & 52.00 & 52.13 \\
\hline
\end{tabular}

Linear correlation plots between the actual and predicted response variables are given in fig. 1 , and their corresponding residual plots showing the scatter of the residuals versus predicted values are given in fig. 2.
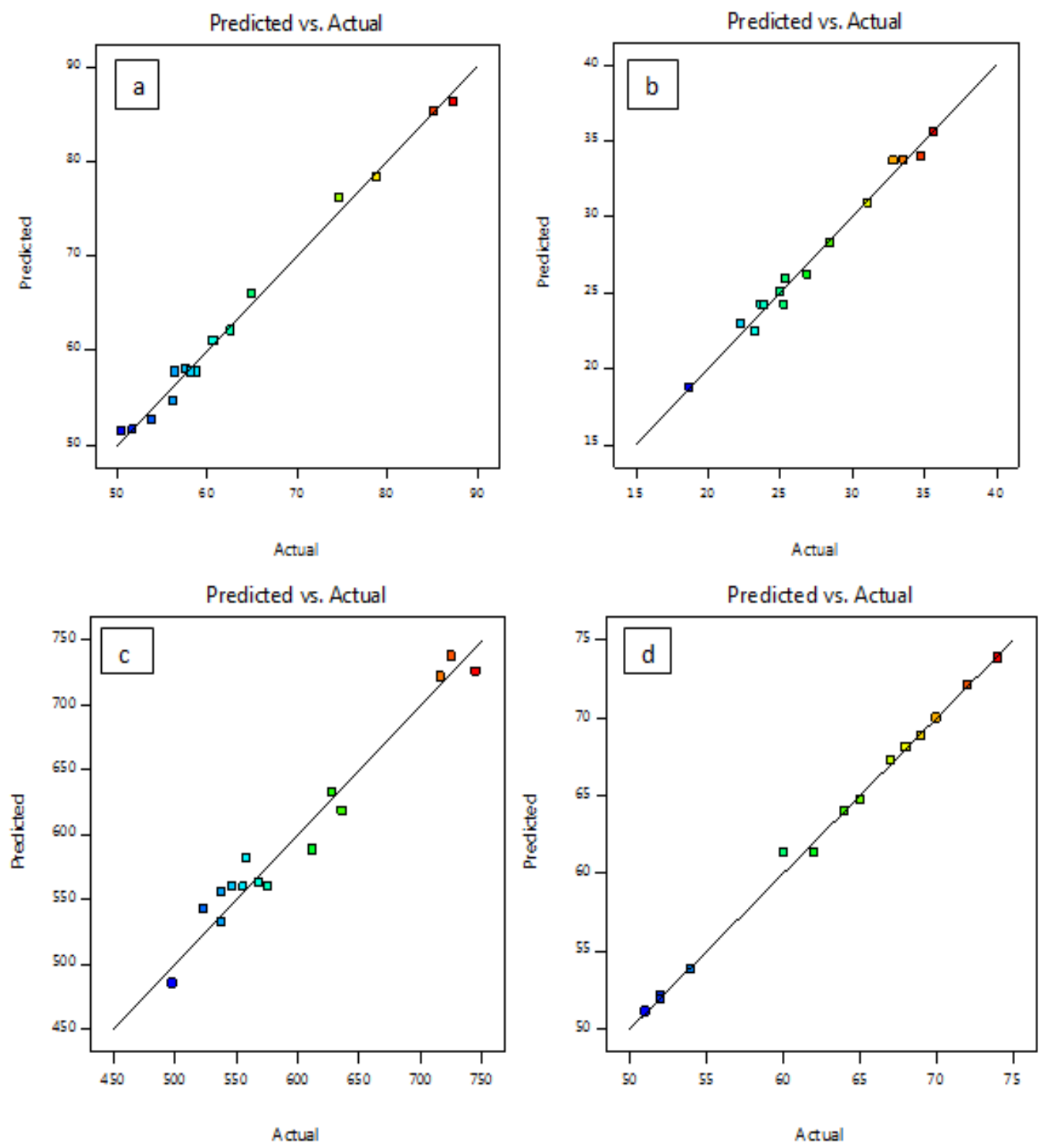

Fig. 1: Linear correlation plots between the actual vs predicted. a)-entrapment efficiency, b)-Q1 $h, c)-t_{90} \%$ and d)-mucoadhesion 

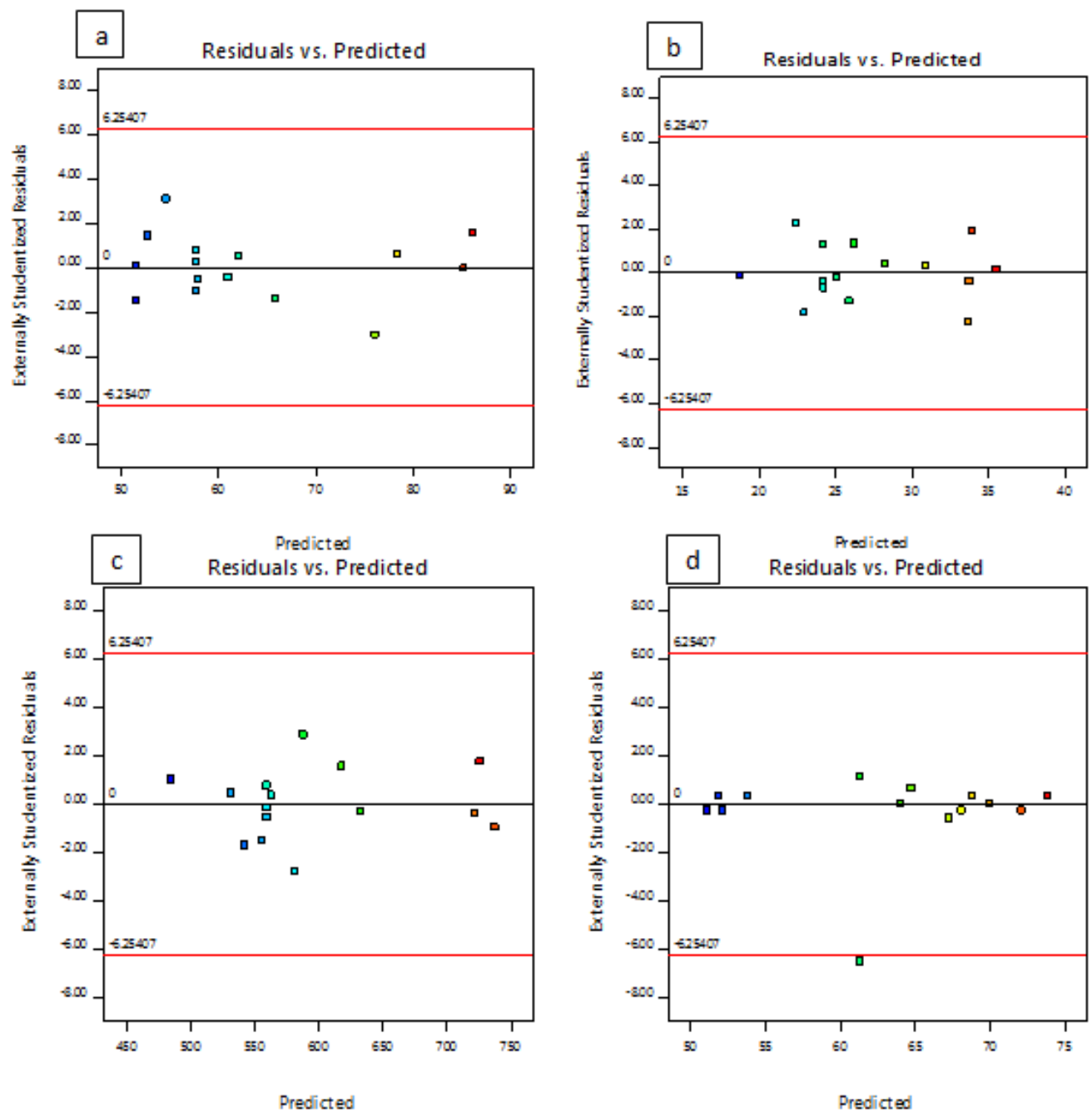

Fig. 2: Showing the scatter of residues vs predicted a)-entrapment efficiency, b)- $\mathrm{Q}_{1} \mathrm{~h}, \mathrm{c}$ )-t90\% and d)-mucoadhesion

Evaluating the main and interaction effects of the independent variables (factors), a three-dimensional response surface graph is very useful. The three-dimensional response surface graph relating drug entrapment efficiency (fig. 3) has shown that increase in drug entrapment with the increase in the amount of ethyl cellulose $\left(\mathrm{X}_{1}\right)$, amount of carbopol 934P $\left(\mathrm{X}_{2}\right)$ and stirring speed $\left(\mathrm{X}_{3}\right)$. The threedimensional response surface graph relating $Q_{1}$ h (fig. 4 ) indicates the increase in the amount of ethyl cellulose $\left(\mathrm{X}_{1}\right)$ and stirring speed $\left(\mathrm{X}_{3}\right)$ percent $\mathrm{Q}_{1} \mathrm{~h}$ is decreasing, however the amount of carbopol 934P $\left(\mathrm{X}_{2}\right)$ increases $\mathrm{Q}_{1} \mathrm{~h}$ and all the thee factors opposes the effect in case of $t_{90 \%}$ (fig. 5). In case of percent mucoadhesion (fig. 6), shown that increase the amount of carbopol 934P $\left(\mathrm{X}_{2}\right)$ mucoadhesion is also increasing, however, increases the amount of ethyl cellulose $\left(\mathrm{X}_{1}\right)$ and stirring speed $\left(\mathrm{X}_{3}\right)$ the mucoadhesion is decreased.

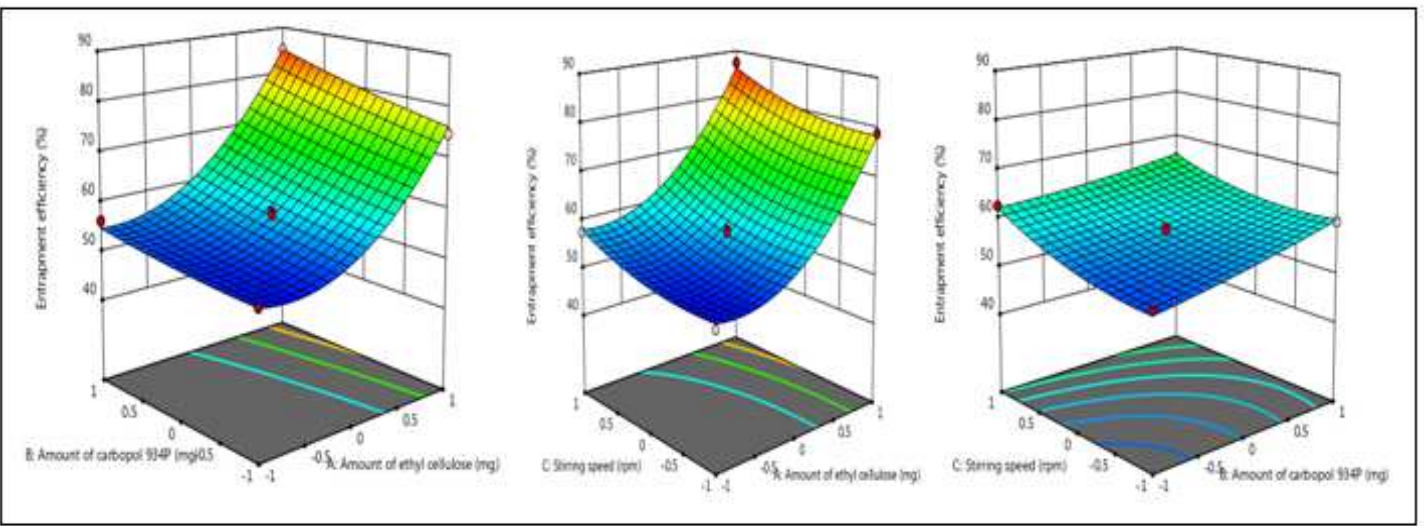

Fig. 3: Thee-dimensional response surface graphs related to drug entrapment efficiency 


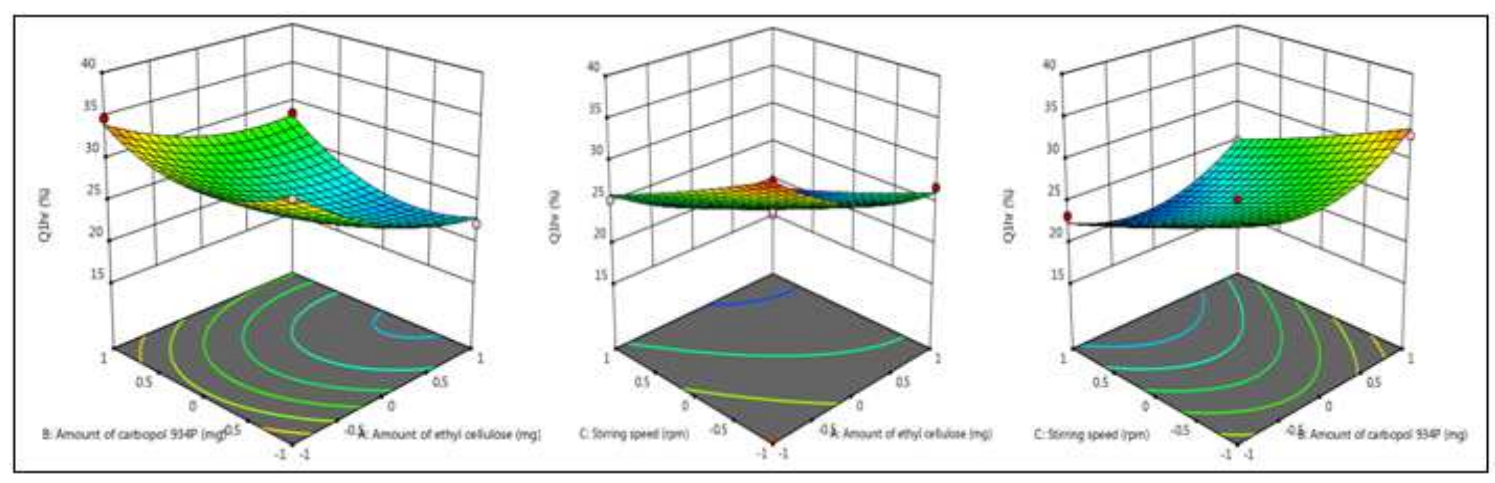

Fig. 4: Thee-dimensional response surface graphs related to $Q_{1} h(\% C D R)$

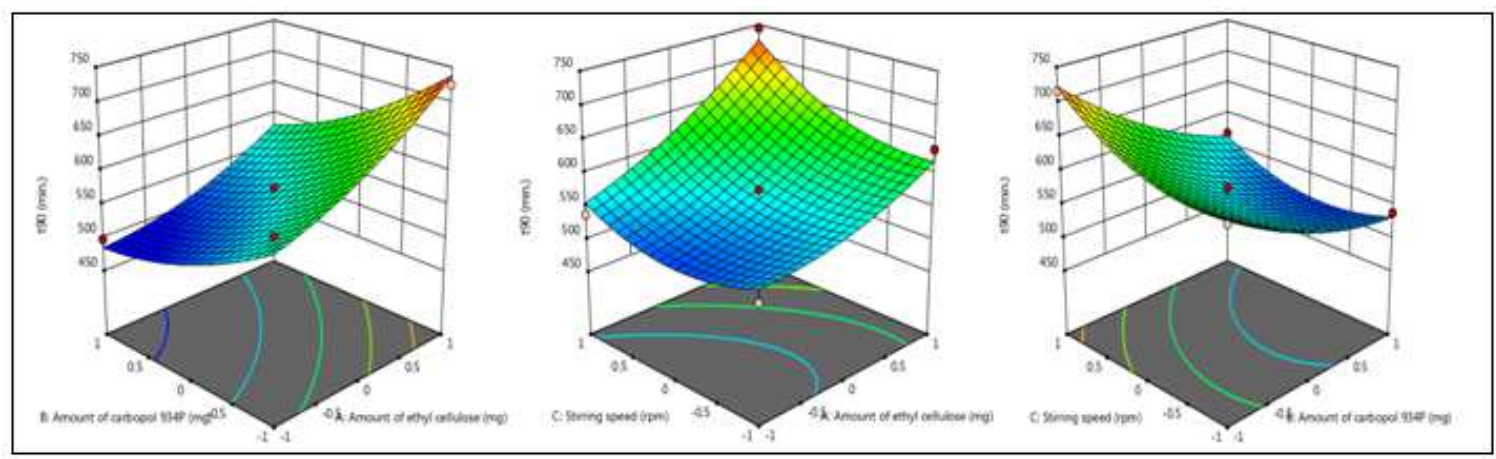

Fig. 5: Thee-dimensional response surface graphs related to $t_{90} \%$

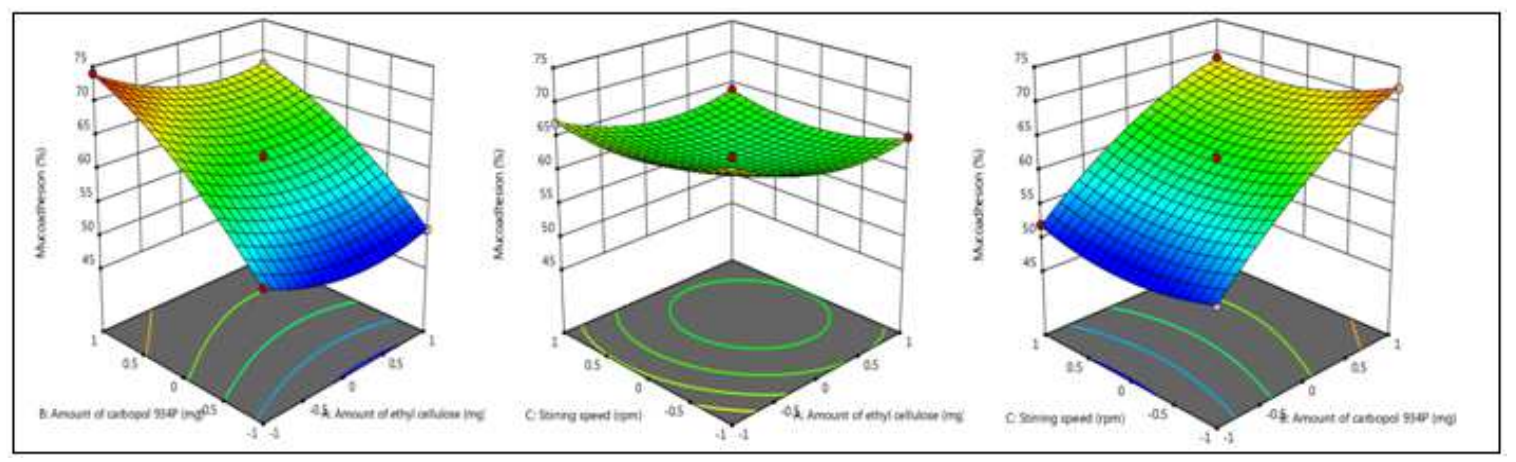

Fig. 6: Thee-dimensional response surface graphs related to mucoadhesion

\section{Percent yield and entrapment efficiency}

The results of percent yield are given in table 3. It is shown that all the coded batches varies from 68.14 to $87.64 \%$ the minimum percentage yield was $68.14 \%$ of batch $\mathrm{V}_{12}$ whereas maximum of $87.64 \%$ of $\mathrm{V}_{4}$ batch.

The entrapment efficiency of all batches was varied from 50.45 to $87.32 \%$ shown in table 2 . The maximum entrapment efficiency was $87.32 \%$ of batch $\mathrm{V}_{4}$. It shows entrapment efficiency is increased due to an increase in the concentration of ethyl cellulose, carbopol 934P and increasing stirring speed. The entrapment efficiency is highly depending on the amount of ethylcellulose used, however other two factors such as the amount of carbopol 934P and stirring speed also increases entrapment efficiency, but in lesser extent as compared to the amount of ethyl cellulose. Similar results have been reported in the literature with other drugs $[43,44]$.

\section{Particle size of microspheres}

The microspheres of all the batches are spherical and free-flowing and the size varies from 92.64 to 124.32 um as shown in table 3 . The size of the microspheres also depends on the concentration of polymer solution and stirring speed. The size of the microspheres was increased by increasing the amount of polymers [45, 46], but decreases with increasing the stirring speed.

\section{In vitro drug release study}

In vitro drug release study carried on all the coded formulations and $\mathrm{Q}_{1} \mathrm{~h}$ and $\mathrm{t}_{90 \%}$ were calculated. The values of $\mathrm{Q}_{1} \mathrm{~h}$ of prepared formulations are 18.72 to $35.66 \%$ and t90\% in the range of 498 to 745 min as shown in table 2 . The amount of ethyl cellulose and stirring speed inversely affects the $\mathrm{Q}_{1} \mathrm{~h}$, although increasing the concentration of carbopol 934P, $\mathrm{Q}_{1} \mathrm{~h}$ is also increased.

Batch $V_{3}$ and $V_{4}$ shows drug release for a long time and batch $V_{1}$ and $\mathrm{V}_{12}$ shows $90 \%$ drug release in less than $525 \mathrm{~min}$. It shows that by increasing the amount of ethyl cellulose and stirring speed the microspheres released drug for a long time while the amount of carbopol 934P reduced drug release. The result agrees with that of Patel J. et al. [21]. The drug release curves of all the batches were shown in fig. 7. 

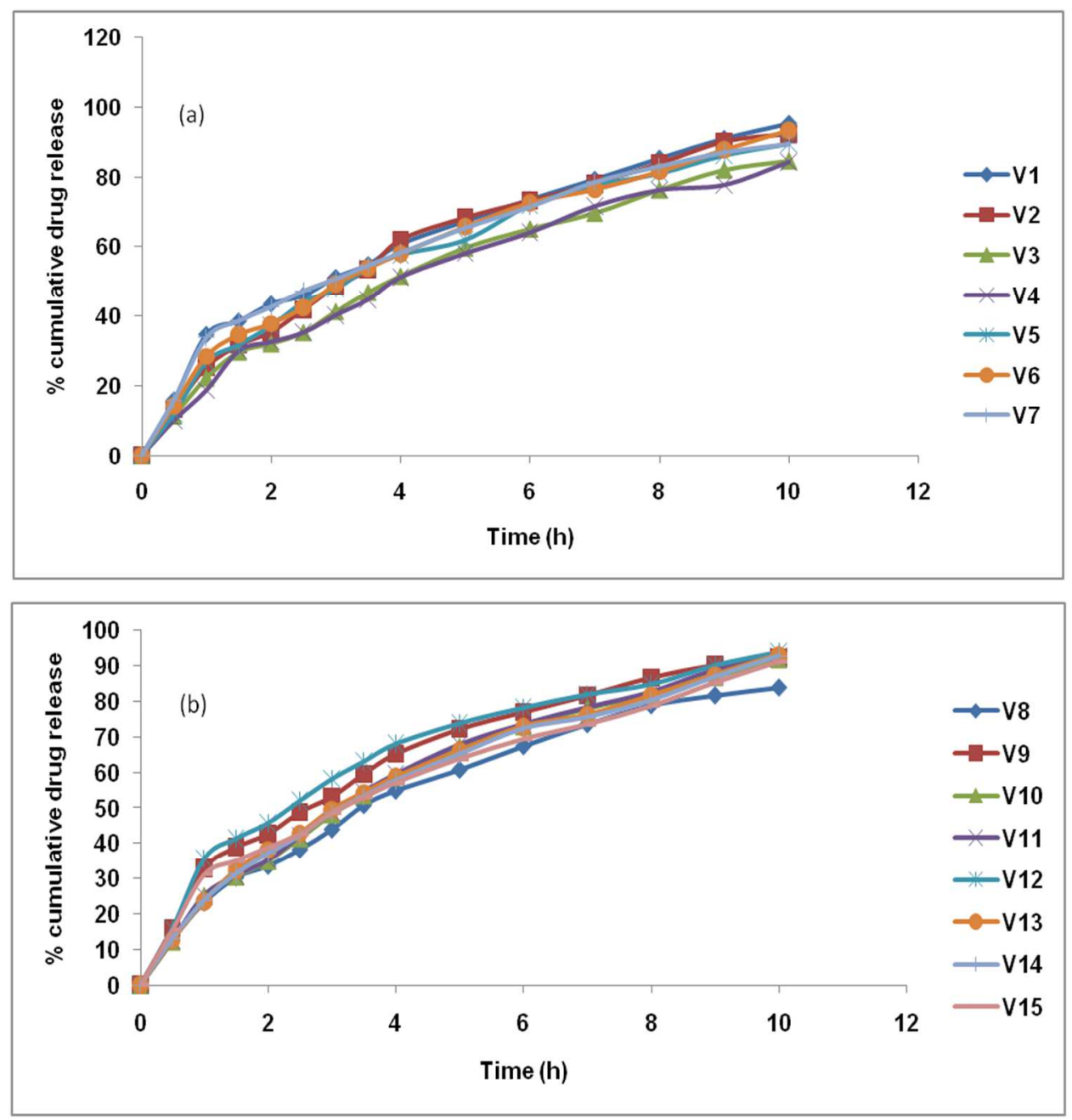

Fig. 7 Drug release profile of batches $(a)-V_{1}-V_{7}$ and $(b)-V_{8}-V_{15}$, mean $\pm S D, n=3$

\section{Percent mucoadhesion}

In vitro wash-off test for percentage mucoadhesion of coded formulations were varied from 51 to $74 \%$. Results of mucoadhesion indicated that the amount of ethyl cellulose and stirring speed had a negative effect on percent mucoadhesion. Mucoadhesion totally depends upon carbopol 934P because it is mucoadhesive polymer and the higher amount of polymer result in a greater amount of free- $\mathrm{COOH}$ (carboxyl group) [47] which are responsible for binding to the sialic acid group inside the mucous network that's why batch $\mathrm{V}_{1}$ and $\mathrm{V}_{9}$ show maximum mucoadhesion as shown in table 2.

\section{Optimized formulation}

Post analysis of the software was used to determine the optimum values of the factors for maximum entrapment, minimum $Q_{1} h$, maximum $t_{90 \%}$ and maximum percent mucoadhesion. Finally, the optimum levels of amount of ethyl cellulose $\left(X_{1}=1\right)$, the amount of carbopol 934P $\left(\mathrm{X}_{2}=0.123\right)$ and stirring speed $\left(\mathrm{X}_{3}=1\right)$ were obtained. These values predict $86.65 \%$ entrapment efficiency, $19.16 \% \mathrm{Q}_{1} \mathrm{~h}, 715 \mathrm{~min} \mathrm{t}_{90 \%}$ and $64.91 \%$ mucoadhesion.

After the confirmation of the optimum batch and their predicted responses, all values were validated by further conducting in vitro studies of mucoadhesive microspheres of valsartan and an average of $85.63 \%$ entrapment efficiency, $20.14 \% \mathrm{Q}_{1} \mathrm{~h}, 730 \mathrm{~min} \mathrm{t}_{90 \%}$ and $66.76 \%$ mucoadhesion. The predicted values and actual responses of the optimized formulation are shown in table 6 and the release profile is shown in fig. 8.

To determine the mechanism of drug release from the optimized formulation, the release profile fitted to zero order, first order, Higuchi equation and Hixon-Crownwell, the ' $\mathrm{R}^{2}$ ' value was found to be 0.966 , $0.974,0.987$ and 0.991 respectively as shown in table 7 . The release

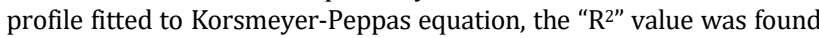
to be 0.998 and " $n$ " value was 0.633 for the optimized batch. It confirmed that the mechanism of drug release was the nonfickian diffusion, may be owing to the swelling of the microspheres.

Table 6: Predicted values and actual responses of optimum formulation

\begin{tabular}{lll}
\hline Response variables & Predicted value & Actual responses \\
\hline$Y_{1}=$ Entrapment efficiency & 86.65 & $85.63 \pm 1.92$ \\
$Y_{2}=Q_{1} h=\%$ cumulative drug release after $1 \mathrm{~h}$ & 19.16 & $20.32 \pm 0.63$ \\
$Y_{3}=t_{90}$ & 715 & 730 \\
$Y_{4}=$ Percent mucoadhesion & 64.91 & 66.76 \\
\hline
\end{tabular}

*mean \pm SD, $\mathrm{n}=3$ 


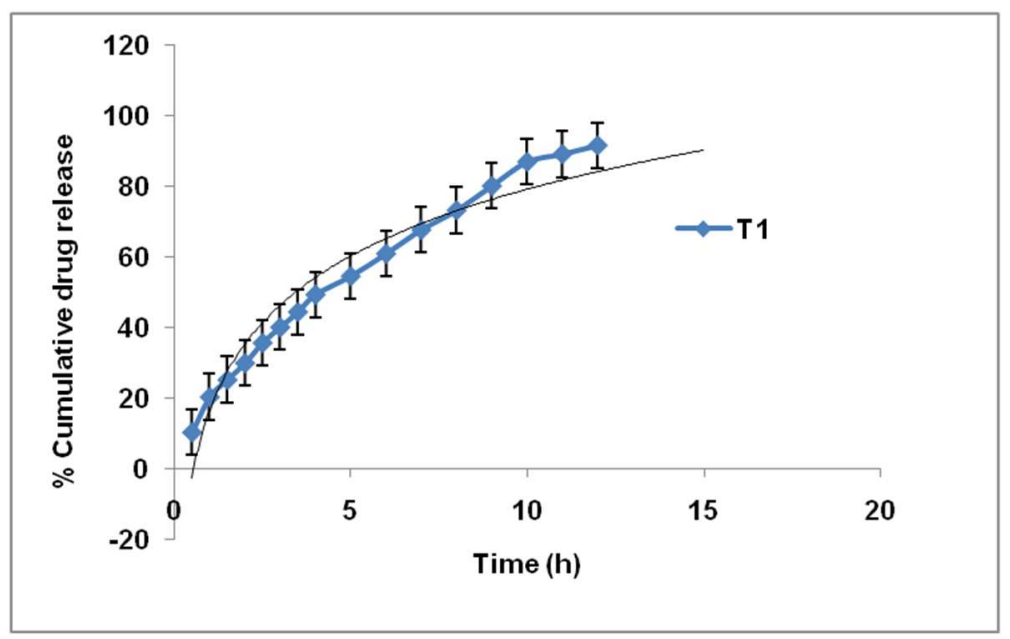

Fig. 8: Release profile of optimized formulation, mean $\pm S D, n=3$

Table 7: Release kinetic data for the batch $\mathrm{T}_{1}$

\begin{tabular}{llllll}
\hline Batch No. & Zero-order kinetics R $^{2}$ & First order kinetics R $^{2}$ & Higuchi kinetics R $^{2}$ & Hixon-crowell R $^{2}$ & Korsmeyer-peppas \\
\hline $\mathrm{T}_{1}$ & 0.966 & 0.974 & 0.987 & 0.991 & 0.998 \\
\hline
\end{tabular}

\section{Surface morphology}

Scanning Electron Microscopic (SEM) analysis of the optimized batch $\left(\mathrm{T}_{1}\right)$ revealed discrete and spherical microspheres. It appeared to have smooth surfaces at higher magnification as shown in fig. 9.

\section{Stability studies of optimized formulation $\left(T_{1}\right)$}

The formulation stored for three months on $40 \pm 2{ }^{\circ} \mathrm{C}$ temperature and $75 \pm 5 \%$ relative humidity. It was found to be stable in between and after three months. The results are shown in table 8.

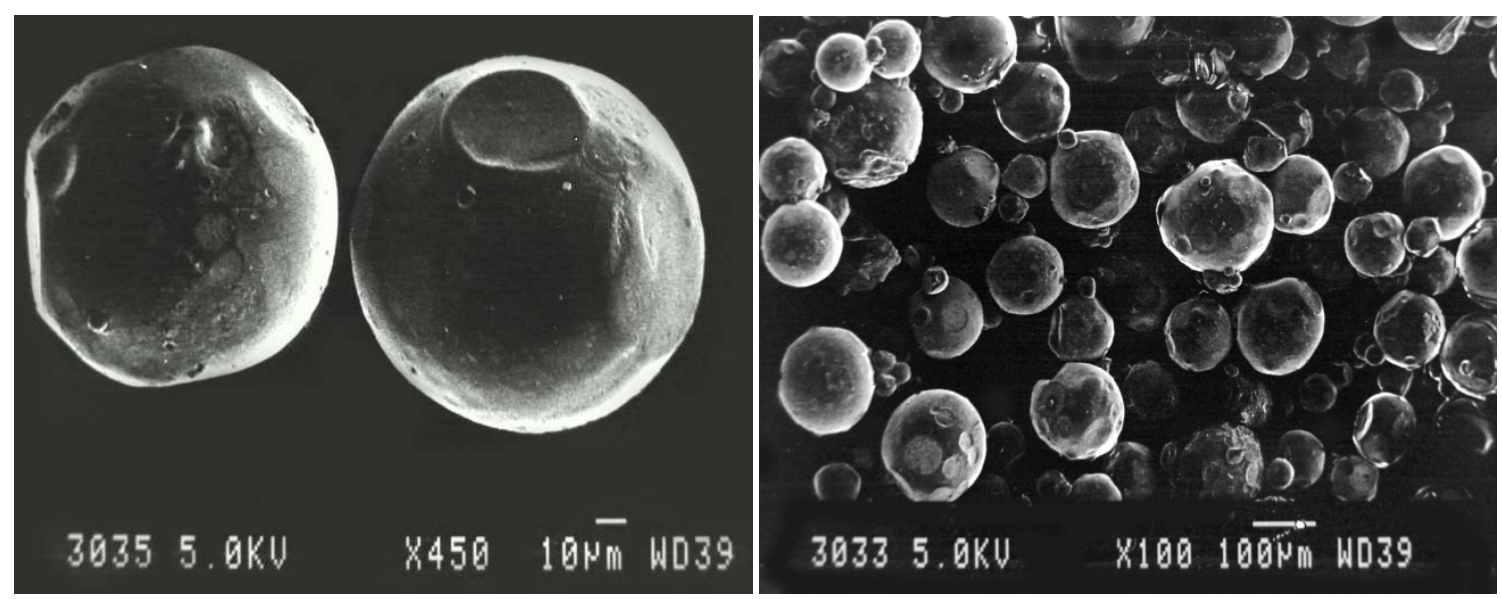

Fig. 9: Scanning electron microscopic images of optimized formulation

Table 8: Accelerated stability studies of optimized formulation

\begin{tabular}{lll}
\hline Response & Initial & \\
\hline$Y_{1}=$ Entrapment efficiency & $85.63 \pm 1.92$ & After 3 mo* $^{*}$ \\
$Y_{2}=Q_{1} h=\%$ cumulative drug release after $1 \mathrm{~h}$ & $20.32 \pm 0.63$ \\
$Y_{3}=t_{90 \%}$ & $732 \pm 2.62$ & $22.04 \pm 2.86$ \\
$Y_{4}=$ Percent mucoadhesion & 724 & 66.76 \\
\hline
\end{tabular}

${ }^{*}$ mean \pm SD, $\mathrm{n}=3$

\section{CONCLUSION}

The entrapment efficiency, $\mathrm{Q}_{1} \mathrm{~h}, \mathrm{t}_{90 \%}$ and percent Mucoadhesion, analyzed though Box-Behnken design significantly affected by independent variables such as the amount of ethyl cellulose $\left(\mathrm{X}_{1}\right)$, amount of carbopol 934P $\left(\mathrm{X}_{2}\right)$ and stirring speed $\left(\mathrm{X}_{3}\right)$. The optimized formulation exhibited drug release of the microspheres is more than $12 \mathrm{~h}$, indicates the microspheres have sustained release Moreover, it has shown high entrapment efficiency and good Mucoadhesion.

Actual responses of the optimized batch have close proximity with the predicted value. SEM analysis revealed that the microspheres of 
spherical in shape and free-flowing and the stability studies of optimum formulation proved that the optimum formulation is stable for a long period of time. All these studies show that the mucoadhesive microspheres of valsartan are excellent alternative over the conventional delivery system.

\section{AUTHORS CONTRIBUTIONS}

All the author have contributed equally.

\section{CONFLICT OF INTERESTS}

\section{Declared none}

\section{REFERENCES}

1. Rahman AM, Hasan R. Hypertension and associated risk factors in some selected rural areas of Bangladesh. Int J Res Med Sci $2014 ; 2: 925$.

2. Misha CP, Kumar S. Risk factors of hypertension in a rural area of Varanasi. Indian J Prev Soc Med 2011;42:101-11.

3. Abebe SM. Prevalence and associated factors of hypertension: a crossectional community-based study in Northwest Ethiopia. PLoS One 2015;10:1-11.

4. Pardeshi CV. Formulation, optimization and evaluation of spray-dried mucoadhesive microspheres as intranasal carriers for valsartan. J Microencapsul 2012;29:103-14.

5. Singh S. Prevalence and associated risk factors of hypertension: a cross-sectional study in urban varanasi hindawi. Int J Hypertens https://doi.org/10.1155/2017/5491838

6. Tabrizi JS. Prevalence and associated factors of prehypertension and hypertension in Iranian population: the lifestyle promotion project (LPP). PLoS One 2016;11:1-15.

7. Oparil S, Schmieder RE. New approaches in the treatment of hypertension. Circ Res 2015;116:1074-95.

8. Saydam M, Takka S. Bioavailability file: valsartan. J Pharm Sci 2007;32:185-96.

9. Siddiqui N. Pharmacological and pharmaceutical profile of valsartan: a review. J Appl Pharm Sci 2011;1:12-9.

10. Shukla S. Formulation and in vitro characterization of alginate microspheres loaded with diloxanide furoate for colon-specific drug delivery. Asian J Pharm 2010;4:199-204.

11. Kakkar R. Formulation and characterization of valsartan proniosomes. Int J Sci Tech 2010;5:146-58.

12. Moffat AC. Clarke's analysis of drugs and poisons. London, UK: Pharmaceutical Press; 2003;3:1692-3.

13. Garud A. Valsartan microcapsules with a coat consisting of alginate and natural cationic polymers. J Pharm Res 2010. p. 271-96.

14. Hagerstorm H. Polymer gels as pharmaceutical dosage forms. Ph. D. Thesis, Faculty of Pharmacy, Uppasala University, Sweden; 2003.

15. Dua K, Trivedi P. Formulation and evaluation of mucoadhesive microspheres of ranitidine hydrochloride using chitosan and sodium carboxymethyl cellulose as polymers. Int J Biomed Res 2013;4:140-4.

16. Ben HL. Bioadhesive polymers for the per-oral delivery of peptide drugs. J Controlled Release 1994;29:329-38.

17. Ben HL. Mucoadhesive excipients for the per-oral delivery of peptide drugs. Eur J Pharm Biopharm 1996;4:117-28.

18. Henriksen I. Bioadhesion of hydrated chitosans: an in vitro and in vivo study. Int J Pharm 1996;145:231-40.

19. Rao SB, Sharma CP. Use of chitosan as a biomaterial: studies on its safety and haemostatic potential. J Biomed Mater Res 1997;34:21-8.

20. Kyada C. Optimization of mucoadhesive microspheres of acyclovir by applying $3^{2}$ full factorial design. J Drug Delivery Sci Tech 2014;24:61-8.

21. Patel J. Formulation and evaluation of propranolol hydrochloride-loaded carbopol-934P/ethyl cellulose mucoadhesive microspheres. Iran J Pharm Res 2010;9:221-32.

22. Satriani AP. Application of box-behnken design in the optimization of glucose production from oil palm empty fruit bunch cellulose. Int J Polym Sci 2013;1-8. http://dx.doi.org/ $10.1155 / 2013 / 104502$.
23. Chowdary KPR, Rao YS. Design and in vitro and in vivo evaluation of mucoadhesive microcapsules of glipizid for oral controlled release a technical note. AAPS PharmSciTech 2003;4:87-92.

24. Jadhav SA, Sharma Y. Mucoadhesive microsphere. Indo Am J Pharm Res 2015;5:3459-70.

25. Yadav VK. Design and evaluation of mucoadhesive microspheres of repaglinide for oral controlled release. Int J Drug Delivery 2011;3:357-70.

26. Abd El-Hameed MD, Kellaway IW. Preparation and in vitro characterization of mucoadhesive polymeric microspheres as intra-nasal delivery systems. Eur J Pharm Biopharm 1997;44:53-60.

27. Kaushik AY. Preparation of floating microspheres of valsartan: in vitro characterization. Int J Res Aurveda Pharm 2015;6:124-30.

28. Desai S. Preparation and in vitro characterization of mucoadhesive microspheres of midazolam: nose to brain administration. Asian J Pharm Clin Res 2011;4:100-2.

29. Khan AB, Thakur RS. Formulation and evaluation of mucoadhesive microspheres of tenofovir disoproxil fumarate for intravaginal use. Curr Drug Delivery 2014;11:112-22.

30. Khan R Formulation and evaluation of mucoadhesive microspheres of flurbiprofe. Pharmacologyonline3 2010;4:1560-6.

31. Garg R, Gupta GD. Gastroretentive floating microspheres of silymarin: preparation and in vitro evaluation. Trop J Pharm Res 2010;9:59-66.

32. Deshmukh MT, Mohite SK. Formulation and characterization of olanzepine-loaded mucoadhesive microspheres. Asian J Pharm Clin Res 2017;10:249-55.

33. Velmurugan S, Ali MA. Development and evaluation of ritonavir mucoadhesive microspheres. Asian J Pharm Clin Res 2014;7:47-52.

34. Nappinnai M, Sivaneswari S. Formulation optimization and characterization of gastroretentive cefpodoxime proxetil mucoadhesive microspheres using $3^{2}$ factorial design. J Pharm Res 2013;7:304-9.

35. Singh B. Correction of raw dissolution data for loss of drug and volume during sampling. Indian J Pharm Sci 1997;59:196-9.

36. Hoodaa A. Optimization and evaluation of gastroretentive ranitidine $\mathrm{HCl}$ microspheres by using design expert software. Int J Biol Macromol 2012;51:691-700.

37. Sabiu S. Indomethacin-induced gastric ulceration in rats: protective roles of spondias mombin and ficus exasperate. J Toxicol Pharmacol 2015;2:261-7.

38. Leh CM. Intestinal transit of bioadhesive microspheres in an in situ loop in the rat-a comparative study with copolymers and blends based on poly (acrylic acid). J Controlled Release 1990;13:51-62.

39. Hardenia SS. Formulation and evaluation of mucoadhesive microspheres of ciprofloxacin. J Adv Pharm Edu Res 2011;1:214-24.

40. Ritger PL, Peppas NA. A simple equation for description of solute release II Fickian and anomalous release from swellable devices. J Controlled Release 1987;5:37-42.

41. Ige PP, Gattani SG. Design and in vitro and in vivo characterization of mucoadhesive matrix pellets of metformin hydrochloride for oral controlled release: a technical note. Arch Pharm Res 2012;35:487-98.

42. Dey S. Formulation and optimization of sustained release stavudine microspheres using response surface methodology. ISRN Pharm 2011. p. 1-7.

43. Maiti S. Investigation on processing variables for the preparation of fluconazole-loaded ethyl cellulose microspheres by modified multiple emulsion technique, AAPS PharmSciTechnol 2009;10:703-15.

44. Venkatesan P. Preparation and evaluation of sustained release loxoprofen loaded microspheres. J Basic Clin Pharmacol 2011;2:159-62.

45. Fu X. Effects of formulation factors on encapsulation efficiency and release behaviour in vitro of huperzine A-PLGA microspheres. J Microencapsul 2005;22:57-66.

46. Kohl S. Ethylcellulose floating microspheres of antidiabetic agent: in vitro and in vivo evaluation. Int J Appl Pharm 2017;9:44-9.

47. Chickering D. Bioadhesive microspheres: characterization and evaluation of bioadhesion involving hard, biodegradable polymers and soft tissue. Reactive Polymers 1995;25:198-206. 